Marquette University

e-Publications@Marquette

4-1-1988

\title{
Acceleration of Wound Healing with High Voltage, Monophasic, Pulsed Current
}

Luther C. Kloth

Marquette University, luther.kloth@marquette.edu

Jeffery A. Feedar

Omni Therapy, Inc.

Published version. Physical Therapy, Vol. 68, No. 4 (April 1988): 503-508. DOI. (C) 1988 American

Physical Therapy Association. Used with permission. 


\title{
Acceleration of Wound Healing with High Voltage, Monophasic, Pulsed Current
}

\author{
LUTHER C. KLOTH \\ and JEFFREY $A$. FEEDAR
}

\begin{abstract}
The purpose of this study was to determine whether high voltage electrical stimulation accelerates the rate of healing of dermal ulcers. Sixteen patients with stage IV decubitis ulcers, ranging in age from 20 to 89 years, participated in the study. The patients were assigned randomly to either a Treatment Group (n = 9) or a Control Group ( $n=7$ ). Patients in the Treatment Group received daily electrical stimulation from a commercial high voltage generator. Patients in the Control Group had the electrodes applied daily but received no stimulation. The ulcers of patients in the Treatment Group healed at a mean rate of $44.8 \%$ a week and healed $100 \%$ over a mean period of 7.3 weeks. The ulcers of patients in the Control Group increased in area an average of $11.6 \%$ a week and increased $\mathbf{2 8 . 9 \%}$ over a mean period of 7.4 weeks. The results of this study suggest that high voltage stimulation accelerates the healing rate of stage IV decubitis ulcers in human subjects.
\end{abstract}

Key Words: Decubitus uicer; Electrotherapy, electrical stimulation; Skin conditions; Wound healing.

The efficacy of various forms of electrical current in augmenting tissue repair has been studied both on human subjects and in animal models. Limited human and animal research has shown that wound healing may be enhanced by applying charged gold leaf to the wound or by passing up to $1.0 \mathrm{~mA}$ of continuous direct current through the wound tissues. $^{1-11}$ Recent anecdotal reports have indicated that crater-type wounds (eg, decubitus ulcers) have responded favorably to electrical stimulation with high voltage stimulation (HVS). A paucity of published research exists on the effectiveness of HVS in promoting wound healing.

In 1688, Digby suggested covering smallpox lesions with charged gold leaf to prevent scarring. 12 Centuries later, charged gold leaf was used by Gallagher and Geschickter for its hemostatic value in vascular surgical procedures. ${ }^{1}$ Kanof found that excessive granulation tissue formed that led to healing complications when burned tissue was treated with gold leaf. ${ }^{2}$ Kanof's report that gold leaf accelerated the healing of decubitus ulcers stimulated Wolf et al to study the clinical efficacy of gold-leaf treatment on 22 ischemic ulcers of 13 patients. ${ }^{3}$ The area of 20 of the ulcers decreased an average of $62 \%$. Three untreated ulcers selected as controls on 3 patients increased in size an average of $96 \%$, but during the same nonspecified time period, gold leaf-treated ulcers of comparable size on the same three patients decreased in size an average of $78 \%$.

Continuous direct current under $1.0 \mathrm{~mA}$ and high voltage,

L. Kloth, MS, is Associate Professor, Program in Physical Therapy, Marquette University, Milwaukee, WI 53233-2269 (USA) and Co-director, Preferred Physical Therapy Services of Wisconsin, SC, 8320 W Bluemound Rd, Ste 213, Milwaukee, W1 53213.

J. Feedar, BS, is Co-director, Preferred Physical Therapy Services or Wisconsin, SC. Ite was Ditector of Therapy Services, Omni Therapy Inc, 1810 Kensington Dr, Waukesha, Wl, when this study was conducted.

This article was submitted October 6, 1986; was with the authors for revision 23 weeks; and was accepted August 3, 1987. Potential Conflict of interest: 2 monophasic, pulsating current have been used by a number of investigators to treat wounds in animals ${ }^{4}{ }^{7.13}$ and in human subjects ${ }^{8-10,14-16}$ and to study the effects of electricity on pathogenic cultures. ${ }^{1,17,1 k}$ Direct current was reported to cause different histological responses beneath the anode and cathode $\mathrm{e}^{4}$ and an increase in wound tensile strength. ${ }^{4-6}$ Carey and Lepley claimed that wound tensile strength was greater at the cathode than at the anode ${ }^{4}$ Wu et al reported that polarity had no influence on tissue tensile strength, although they indicated that tensile strength was greater in wounds with stainless steel sutures than with platinum sutures, regardless of whether continuous direct current was passed through the sutures. ${ }^{5}$ Assimacopoulos treated induced wounds in rabbits with continuous direct current from the cathode and reported a $25 \%$ decrease in healing time. ${ }^{6}$ Direct current applied from the anode to induced skin wounds in pigs was reported to significantly increase collagen synthetic capacity and the rate of wound epithelialization. ${ }^{7}$

Several studies of human subjects showed that low intensity, continuous direct current of 0.2 to $1.0 \mathrm{~mA}$ applied from the anode four to six hours daily promoted the healing of dermal ulcers. ${ }^{8-10}$ Two studies using similar electrotherapeutic protocols reported that treated wounds healed at a rate of $9 \%$ to $30 \%$ a week during treatment periods that averaged 6.7 weeks. ${ }^{8,9}$ Wolcott et al treated 75 ulcers with electrical current and reported that $40 \%$ of the wounds healed in an average of 9.6 weeks. ${ }^{8}$ Ulcers that healed completely in their study healed at a rate of $18.4 \%$ a week, compared with a rate of $9.3 \%$ a weck for ulcers that did not heal completely. Eight of the bilaterally treated and untreated ulcers healed at a wcekly rate of $27 \%$ and $5 \%$, respectively. " Paraplegic patients in the Wolcott et al study with lesions in decentralized or dencrvated tissue showed nearly a $40 \%$ slower healing rate in response to electrotherapeutic treatment than patients with no apparent neuropathy. "Gault and Gatens reported that lesions treated 
with direct current healed twice as fast as their untreated counterparts. ${ }^{9}$ More recently, Carley and Wainapel reported that indolent ulcers treated with 200 to $800 \mathrm{~mA}$ of direct current healed 1.5 to 2.5 times faster than untreated ulcers. ${ }^{10}$

Several investigators reported that cathodal ${ }^{8-11,18}$ or anodal ${ }^{11}$ stimulation with a continuous, low intensity direct current has a bactericidal effect both in vitro and in vivo. Researchers in most studies of human subjects, however, have used the cathode from a continuous direct current source for its antibacterial effect. ${ }^{8-10}$

Four reports in the literature were found that used HVS to promote the healing of injured tissue. ${ }^{13-16}$ Young applied HVS to the hind limb of four dogs that had their hind limb circulation compromised for 12 hours by proximal application of a tourniquet. ${ }^{13}$ Twenty-four hours after tourniquet removal, each dog was treated for five minutes daily for 14 days with $150 \mathrm{~V}$ of HVS at a frequency of 12 to $14 \mathrm{~Hz}$ and a pulse duration of $4 \mu \mathrm{sec}$. A control group of four dogs did not receive electrical stimulation after tourniquet removal. The hind limbs of dogs in the control group developed pronounced edema, superficial necrosis, and eventually moist gangrene. Dogs in the treatment group walked without limping at the end of the study and had no observable differences between the normal and traumatized hind limb. All of the dogs in the control group developed severe gangrene. ${ }^{13}$

In a case report, Thurman and Christian attributed the healing of a purulent septic abscess on the foot of a 43-yearold female patient with juvenile onset diabetes mellitus to HVS treatment. They applied electrodes around the patient's abscess and elicited muscular contractions at a low pulse frequency to improve blood flow. The abscess responded favorably to treatments administered twice daily on weekdays and once daily on weekends. Amputation of the patient's limb was unnecessary, and the wound healed completely in six months. ${ }^{14}$

Akers and Gabrielson studied the rate of decubitus wound healing in human subjects using three different procedures. Fourteen patients with decubitis ulcers were assigned to one of three treatment groups: 1) whirlpool bath once a day, 2) combination of whirlpool bath and HVS twice a day, and 3) HVS twice a day. The distribution of patients between groups, duration and number of treatments, and stimulus characteristics were not reported. Akers and Gabrielson indicated that patients who received only HVS treatment experienced the greatest rate of change in wound size followed by patients who received both whirlpool and HVS treatments. Patients who received whirlpool treatment alone experienced the least change. ${ }^{15}$

In two case studies involving HVS following podiatric surgery, Ross and Segal implied that HVS was used to enhance tissue healing. Although the treatment protocol was given for the use of HVS, the only reported benefits were pain and edema reduction, with no mention of the effects of HVS on tissue healing. ${ }^{16}$

These reports provide insufficient evidence that HVS promotes the healing of chronic wounds. The purpose of this study was to determine whether HVS enhances the rate of healing of various types of dermal ulcers. If HVS can be shown to accelerate wound healing, physical therapists could use HVS as a means of electrical stimulation for tissue repair (ESTR) of chronic wounds.

Based on the available information regarding the use of therapeutic electricity for accelerating wound healing, we hypothesized that HVS would produce a greater increase in the healing rate and percentage of healing of crater-type dermal ulcers than a sham application of HVS to dermal ulcers.

\section{METHOD}

\section{Subjects}

Sixteen patients between 20 and 89 years of age were selected for the study. The mean age of patients in the Treatment and Control Groups was $71 \pm 21$ years and $66 \pm$ 21 years, respectively. All patients in the study had intact peripheral nervous systems and stage IV ulcers that had eroded into or through muscle. To reduce investigator bias, a person not involved in the study tossed a coin to assign patients to the Treatment Group ( $\mathrm{n}=9$ ) or the Control Group $(\mathrm{n}=7)$.

A subgroup of three patients initially assigned to the Control Group whose ulcers did not heal were later reassigned arbitrarily to the Treatment Group to determine whether their ulcers would respond to HVS treatment. Wound duration for these three patients before the study began ranged from 1 month to 2.5 years. The ulcers of all patients in the Treatment and Control Groups had been unresponsive to previous trcatments administered by other health care personnel. All patients indicated their approval to participate in the study by signing an informed consent form.

\section{Materials}

We used a DynaWave ${ }^{\infty}$ Model 12 high voltage, monophasic twin-pulsed generator in this study and arbitrarily set the stimulus variables at a frequency of $105 \mathrm{~Hz}$, an intraphase interval of $50 \mu \mathrm{sec}$, and a voltage just below that capable of producing a visible muscle contraction (100-175 V). At 100 $\mathrm{V}$ with an intraphase interval of $100 \mu \mathrm{sec}$, the single-phase charge was calculated at about $1.6 \mu \mathrm{C}$ with a total-pulse charge accumulation of $342 \mu \mathrm{C} / \mathrm{sec}$.

\section{Procedure}

Patients in the Treatment Group received 45 minutes of ESTR applied to the ulcer site once a day, five days a week. Patients in the Control Group had electrodes applied in the same manner as patients in the Treatment Group, but the voltage was maintained at zero. Sham treatments were given for periods of 4,5 , and 16 weeks to three patients in the Control Group. The wound dimensions of these three patients either increased or did not change in size after the sham treatment period, and they were then reassigned to the Treatment Group.

All patients who had ulcers caused by pressure against the skin used a pressure-relieving device that rcduced exogenous cutaneous pressure. All patients took a high-protein dietary supplement to help offset nitrogen loss from wound protein breakdown.

We debrided necrotic tissue from the wounds of patients in both groups manually and with enzymes. Thick eschar and the outermost necrotic tissue were debrided manually. A proteolytic enzyme ointment, Elase ${ }^{i 0}$, was appliod twice daily for the first three days of treatment to sclectively digest the

\footnotetext{
* DynaWave Corp, 2520 Kaneville Ct, Geneva, IL 60134.

$\dagger$ Parke-Davis, Div of Wamer-Lambert Co, 201 Tabor Rd. Morris Plains, N.J 07950.
} 
necrotic protein. Any remaining necrotic collagen was debrided on the fourth treatment day with a collagenase enzyme ointment, Biozyme-C ${ }^{\circ} .{ }^{\ddagger}$ The wound was packed with salinemoistened gauze during enzymatic debridement to absorb slough and was covered with plastic wrap to retain moisture. We continued the debridement procedure until the wound was free of necrotic tissue, and we then applied a transparent dressing (Tegaderm ${ }^{\circledR)}$ ) over the wound to retain moisture until the healing was complete.

Enzyme residues were flushed from the wound with a saline solution before electrode placement, and the wound was packed loosely and covered with sterile, saline-saturated gauze sponges to enhance electrical conductivity. We initially placed the positive electrode over the wound. The edge-to-edge distance between the anode and the cathode was maintained at $15 \mathrm{~cm}$ with the anode cephalad to the cathode and close to the neuraxis (Fig. 1). This electrode placement was maintained unless the patient reached a plateau in wound healing.

Four patients in the Treatment Group reached an initial healing plateau; the cathode was then moved over the wound, and the anode was repositioned $15-\mathrm{cm}$ cephalad. When the same patients reached a second healing plateau, electrode polarity on the wound was alternated daily. The application of electrodes always complied with the scheme of having the anode cephalad and closer to the neuraxis than the cathode to amplify the injury potential as suggested by Becker. ${ }^{19}$

\section{Data Analysis}

The same physical therapist (J.A.F.) recorded surface area wound dimensions for each patient before treatment and at weekly treatment intervals. The physical therapist placed plastic wrap over the wound and traced the wound's perimeter with a fine-tipped transparency marker (Fig. 2). The physical therapist traced each wound three times to establish measurement reliability, placed the tracings over carbon paper, and transcribed the tracings onto metric graph paper (Fig. 3). The three tracings of each wound were superimposed on the graph paper to determine the degree of accuracy of the measurements. The close agreement of the tracings indicated that the measurement procedure was reliable.

The number of square millimeters on the metric graph paper within the wound tracing were counted to determine the wound area to the nearest hundredth of a square centimeter. We analyzed wound area weekly by determining the percentage of change in wound dimensions. The number of square millimeters in the wound tracing taken at weekly intervals was divided by the number of square millimeters in the wound tracing before treatment began. We used this figure to calculate the percentage of reduction or increase in wound size between weeks. We took $35-\mathrm{mm}$ macro slides at weekly intervals to further document wound dimensions.

\section{RESULTS}

Table 1 summarizes data for the nine patients in the Treatment Group. The mean pretreatment wound area for patients in the Treatment Group was $4.1 \mathrm{~cm}^{2}$. The mean posttreatment wound area was $0 \mathrm{~cm}^{2}$, because all wounds healed completely. The mean length of treatment was 7.3 weeks, during which time the mean healing rate was $45 \%$ a week.

‡ Armour Pharmaceutical Co, PO Box 511, Kankakee, IL 60190.

$\S 3 \mathrm{M}$, Medical Products Div, Bldg 225-5S-01, 3M Center, St. Paul, MN 55144-1000.

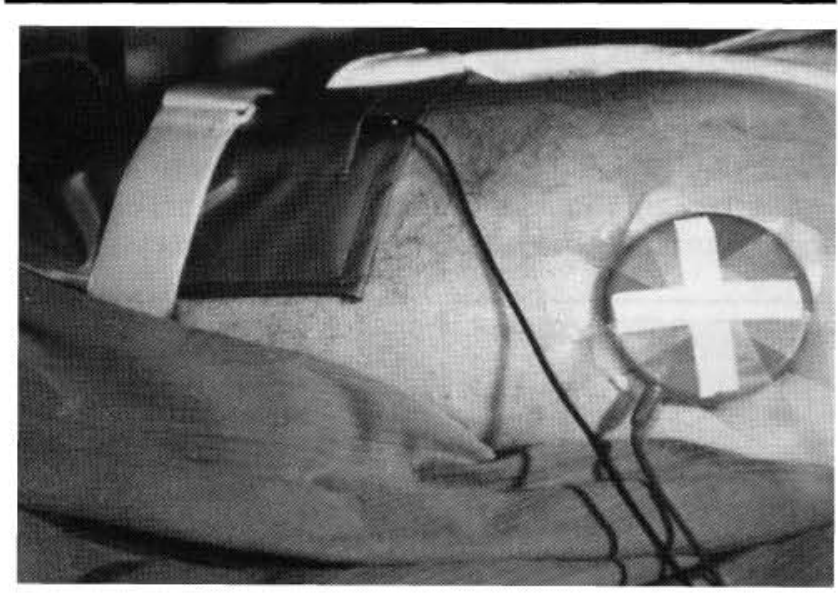

Fig. 1. Placement of electrodes on wound cite showing the relationship of the anode and cathode to the neuraxis.

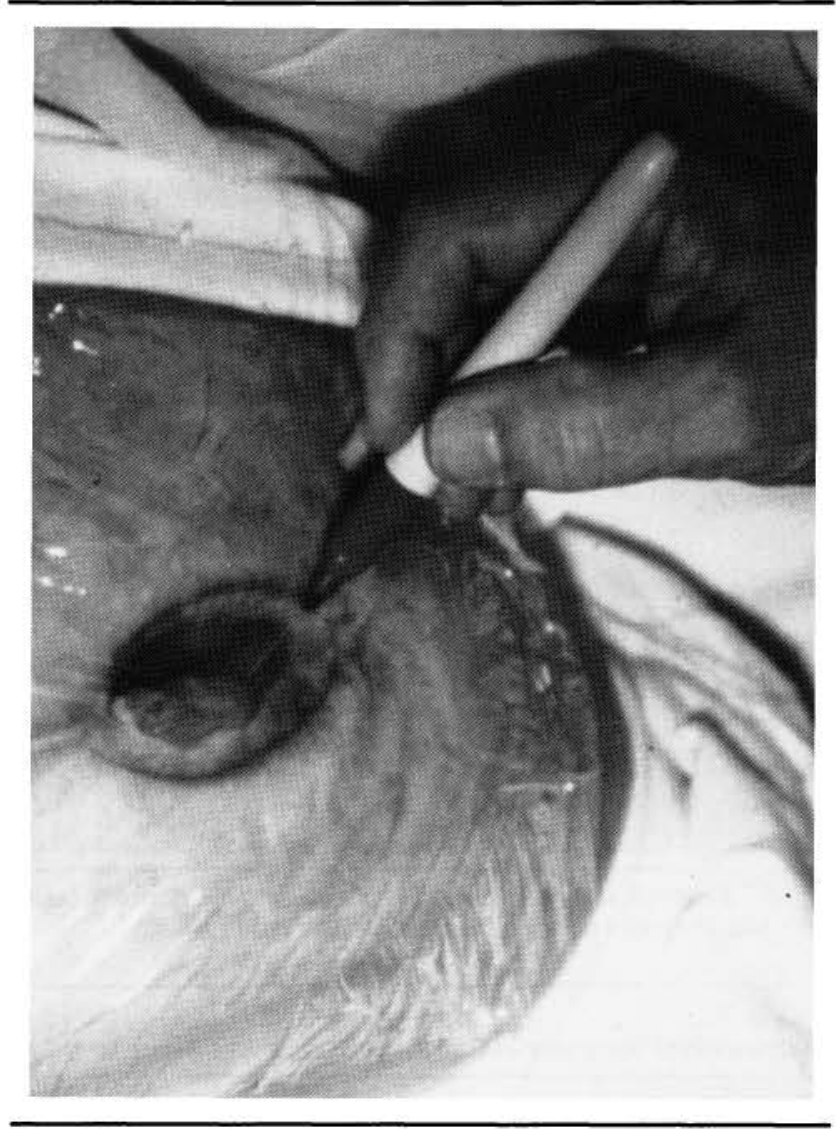

Fig. 2. Tracing of wound perimeter onto plastic wrap with a finetipped marker to determine wound area dimension.

Figures 4 and 5 show the wound of one patient from the Treatment Group before and after 10 weeks of ESTR.

Data for the seven patients in the Control Group are summarized in Table 2 . The mean pretreatment wound area for patients in the Control Group was $5.2 \mathrm{~cm}^{2}$. The mean posttreatment wound area was $6.1 \mathrm{~cm}^{2}$. During a mean length of treatment of 7.4 weeks, wounds increased in area by a mean of $11.6 \%$ between consecutive weeks because of tissue erosion. The wound area for all patients in the Control Group increased a mean of $28.9 \%$ between the first and last sham treatments. The stasis ulcer of one patient in the Control 
Group increased so dramatically in size $(242.4 \%)$ that we decided to recalculate the Control Group data on total percentage surface area change and healing rate weekly percentage omitting his data. This recalculation resulted in a mean decrease in wound surface area of $-6.6 \%$ between the first and last sham treatments and a $10 \%$ reduction in healing rate for the remaining six patients in the Control Group.

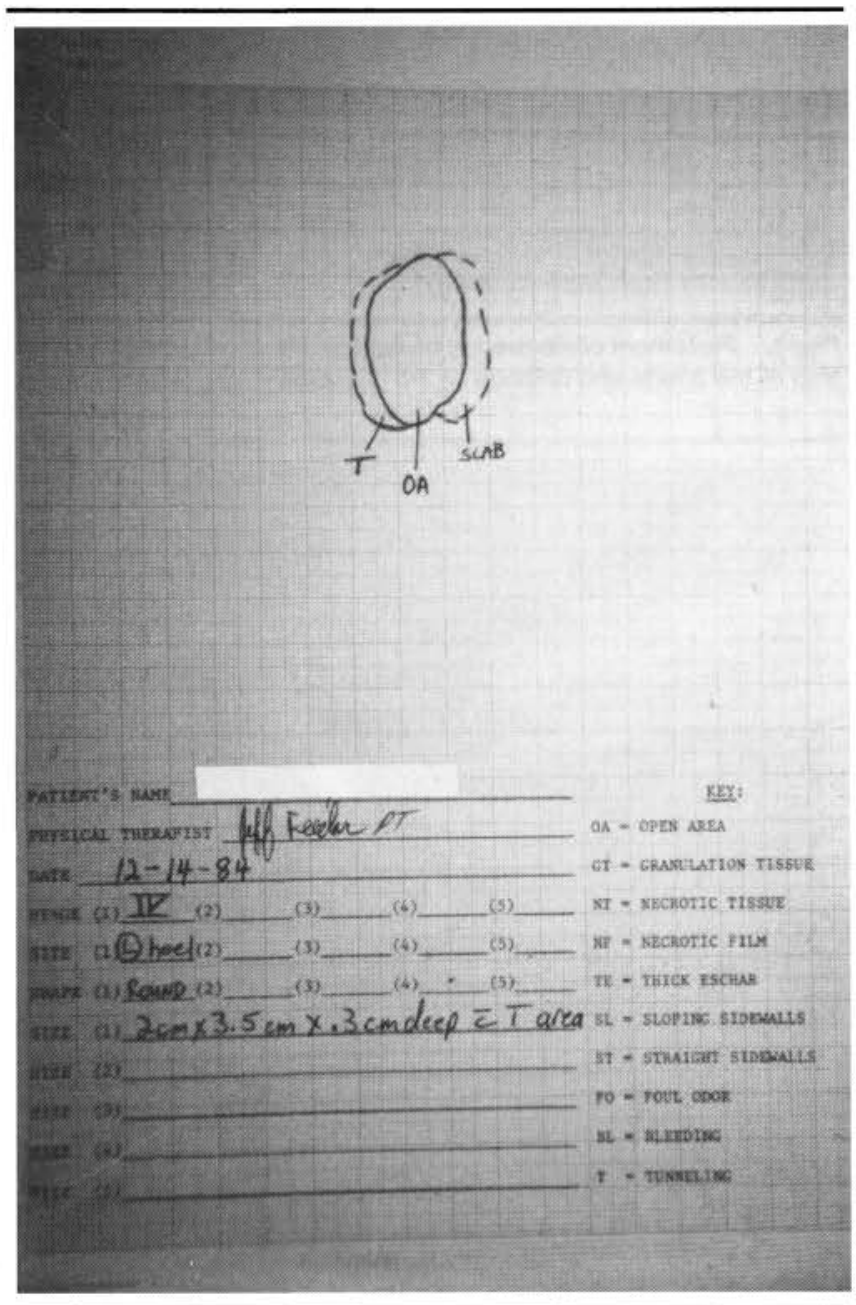

Fig. 3. Patient's wound tracing transposed onto metric graph paper from plastic wrap tracing to measure wound area.
The posttreatment data of three patients from the Control Subgroup who were later reassigned to the Treatment Subgroup are shown in Tables 3 and 4 , respectively. The mean healing rate for patients in the Control Subgroup was $+1.8 \%$ a week (wounds increased in size) with a total area increase of $+1.2 \%$ during 8.7 weeks. The patients' wounds healed by $38.1 \%$ a week after they were reassigned to the Treatment Subgroup with $100 \%$ healing over 8.3 weeks.

\section{DISCUSSION}

The results of this study supported our hypothesis and the results of other studies showing that electricity enhances the rate and extent of wound healing. ${ }^{8-10,15}$ Comparisons of our findings with other clinical reports that used low intensity direct current ${ }^{8-10}$ and HVS $^{15,16}$ for wound healing indicate that the HVS treatment time required to satisfactorily augment tissue healing does not need to exceed 60 minutes five times a week. The average rate of wound healing of $44.8 \%$ a week in our study, compared with $13.4 \%$ a week reported by Wolcott et $\mathrm{al}^{8}{ }^{8}$ suggests that our study protocol may decrease the length of patients' institutional stay and treatment costs. Additional HVS studies are needed to determine the optimal number and duration of HVS treatment on chronic dermal ulcers using our stimulus variables and those of other researchers.

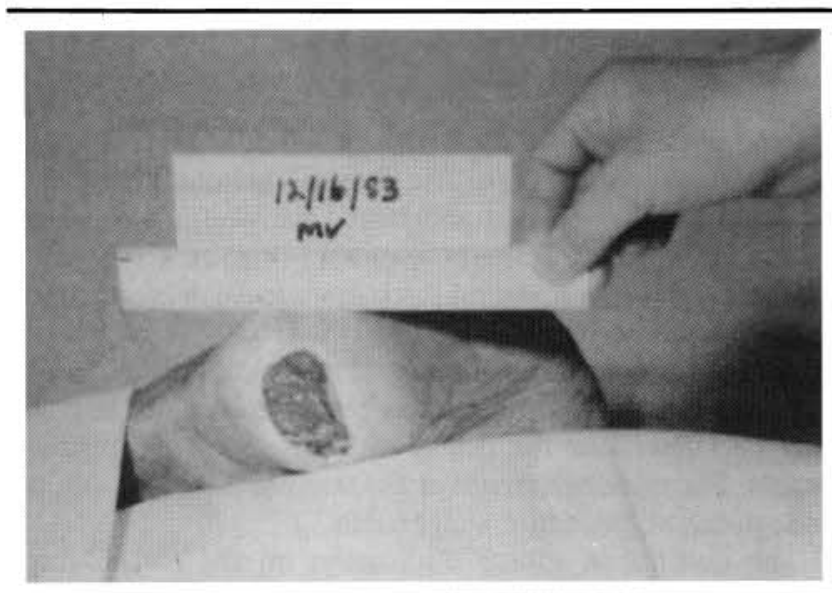

Fig. 4. Decubitis ulcer of patient in the Treatment Group before high voltage stimulation.

TABLE 1

Posttreatment Summary of Patients in Treatment Group $(n=9)$

\begin{tabular}{llccccc}
\hline \multicolumn{1}{c}{ Primary Diagnosis } & $\begin{array}{c}\text { Age } \\
(\mathbf{y r})\end{array}$ & $\begin{array}{c}\text { Pretreatment } \\
\text { Wound Area } \\
\left(\mathrm{cm}^{2}\right)\end{array}$ & $\begin{array}{c}\text { Length of } \\
\text { Treatment } \\
(\mathbf{w k})\end{array}$ & $\begin{array}{c}\text { Healing } \\
\text { Rate } \\
(\% / \text { wk })\end{array}$ & $\begin{array}{c}\text { Posttreatment } \\
\text { Wound Area } \\
\left(\mathrm{cm}^{2}\right)\end{array}$ & $\begin{array}{c}\text { Total Ulcer Surface } \\
\text { Area Change } \\
(\%)\end{array}$ \\
\hline CVA $^{a}$ & 63 & 2.40 & 5.0 & 59.80 & 0 & 100 \\
CVA & 85 & 0.24 & 4.0 & 21.65 & 0 & 100 \\
PVD & 85 & 0.26 & 11.0 & 21.43 & 0 & 100 \\
PVD & 52 & 5.64 & 7.0 & 39.40 & 0 & 100 \\
Lower extremity fracture & 83 & 0.88 & 6.0 & 45.51 & 0 & 100 \\
Pilonidal cyst & 20 & 4.60 & 2.0 & 92.39 & 0 & 100 \\
Above knee amputee-diabetes & 79 & 1.57 & 5.0 & 65.72 & 0 & 100 \\
Diabetes-fracture & 75 & 5.63 & 10.0 & 32.81 & 0 & 100 \\
Diabetes-fracture & 89 & 15.55 & 16.0 & 24.55 & 0 & 100 \\
\hline $\bar{X}$ & 70.13 & 4.08 & 7.33 & 44.80 & 0 & 100 \\
$s$ & 20.9 & 4.5 & 4.0 & 22.6 & & \\
\hline
\end{tabular}

a CVA = cerebrovascular accident.

${ }^{\circ}$ PVD $=$ peripheral vascular disease. 


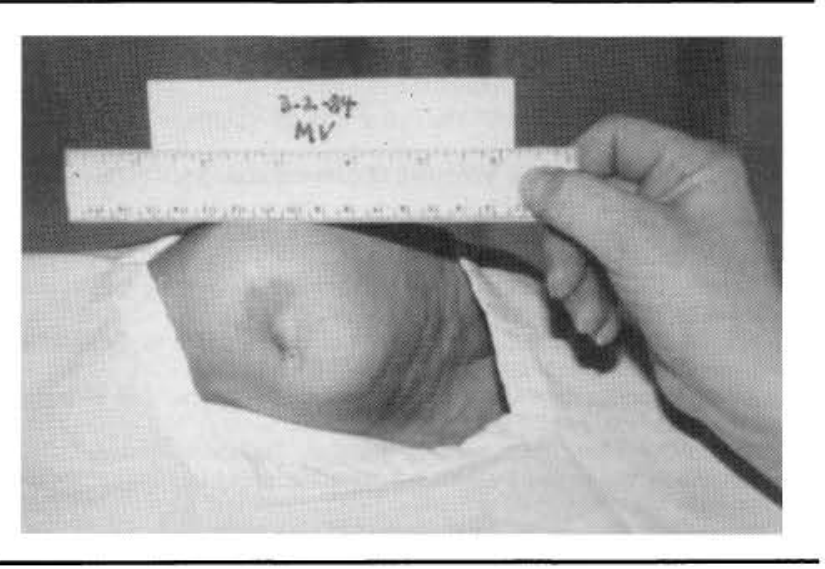

Fig. 5. Healed decubitis ulcer of patient in Figure 4 after 10 weeks of high voltage stimulation.
Becker suggested that the apparent ability of anodal direct current to augment healing of dermal ulcers results from the ability of the stimulus to amplify the local positive injury content. By boosting the magnitude of the wound injury potential with the anode, Becker hypothesized that the input "error" signal to the central nervous system may provide a return neural signal that activates a mechanism for tissue growth and repair. ${ }^{19}$ In this study and earlier studies on human subjects, the anode was placed on the wound, and no study was found in which the cathode was placed on the wound of human subjects. Brown and Gogia recently examined the effects of HVS on cutaneous wound healing in rabbits and found that cathodal stimulation did not significantly improve, and may have hampered, the wound healing process in experimental animals. ${ }^{20}$

In our study and other studies, ${ }^{5-10}$ the polarity of the treatment electrode was alternated during the course of treat-

TABLE 2

Posttreatment Summary of Patients in Control Group $(n=7)$

\begin{tabular}{lcccccc}
\hline $\begin{array}{c}\text { Primary } \\
\text { Diagnosis }\end{array}$ & $\begin{array}{c}\text { Age } \\
(\mathrm{yr})\end{array}$ & $\begin{array}{c}\text { Wound Area } \\
\left(\mathrm{cm}^{2}\right)\end{array}$ & $\begin{array}{c}\text { Length of } \\
\text { Treatment } \\
(\mathbf{w k})\end{array}$ & $\begin{array}{c}\text { Healing or } \\
\text { Erosion Rate } \\
(\% / w k)^{a}\end{array}$ & $\begin{array}{c}\text { Wound Area } \\
\left(\mathrm{cm}^{2}\right)\end{array}$ & $\begin{array}{c}\text { Total Surface } \\
\text { Area Change }\end{array}$ \\
$(\%)$
\end{tabular}

${ }^{a}$ Positive numbers represent an increase in wound surface area and erosion rate.

${ }^{\circ} \mathrm{CVA}=$ cerebrovascular accident.

${ }^{c}$ Healing rate weekly percentage recalculated with stasis ulcer data omitted $(\bar{X}=10.03 ; s=19.8)$.

${ }^{d}$ Total surface area percentage of change recalculated with stasis ulcer data omitted $(\bar{X}=6.65 ; s=23.2)$.

TABLE 3

Posttreatment Summary of Patients in Control Subgroup $(n=3)$

\begin{tabular}{lcccccc}
\hline $\begin{array}{c}\text { Primary } \\
\text { Diagnosis }\end{array}$ & $\begin{array}{c}\text { Age } \\
(\mathbf{y r})\end{array}$ & $\begin{array}{c}\text { Wound Area } \\
\left(\mathrm{cm}^{2}\right)\end{array}$ & $\begin{array}{c}\text { Length of } \\
\text { Treatment } \\
(\mathbf{w k})\end{array}$ & $\begin{array}{c}\text { Healing or } \\
\text { Erosion Rate } \\
(\% / w k)^{a}\end{array}$ & $\begin{array}{c}\text { Wound Area } \\
\left(\mathrm{cm}^{2}\right)\end{array}$ & $\begin{array}{c}\text { Total Surface } \\
\text { Area Change }\end{array}$ \\
$(\%)$
\end{tabular}

a Positive numbers represent an increase in wound erosion rate and surface area.

${ }^{\circ} \mathrm{CVA}=$ cerebrovascular accident.

TABLE 4

Posttreatment Summary of Patients in Treatment Subgroup $(n=3)$

\begin{tabular}{|c|c|c|c|c|c|c|}
\hline $\begin{array}{l}\text { Primary } \\
\text { Diagnosis }\end{array}$ & $\begin{array}{l}\text { Age } \\
\text { (yr) }\end{array}$ & $\begin{array}{l}\text { Wound Area } \\
\left(\mathrm{cm}^{2}\right)\end{array}$ & $\begin{array}{l}\text { Length of } \\
\text { Treatment } \\
\text { (wk) }\end{array}$ & $\begin{array}{l}\text { Healing Rate } \\
(\% / w k)\end{array}$ & $\begin{array}{l}\text { Wound Area } \\
\left(\mathrm{cm}^{2}\right)\end{array}$ & $\begin{array}{c}\text { Total Surface } \\
\text { Area Change } \\
(\%)\end{array}$ \\
\hline $\mathrm{CVA}^{a}$ & 63 & 2.40 & 5.0 & 59.80 & 0 & 100 \\
\hline CVA & 85 & 0.24 & 4.0 & 21.65 & 0 & 100 \\
\hline Diabetes-fracture & 75 & 5.63 & 16.0 & 32.81 & 0 & 100 \\
\hline $\bar{x}$ & 74.33 & 2.76 & 8.33 & 38.09 & 0 & 100 \\
\hline$s$ & 8.9 & 2.2 & 5.4 & 16.0 & & \\
\hline
\end{tabular}

${ }^{\circ} \mathrm{CVA}=$ cerebrovascular accident. 
ment. Because studies have shown that skin battery potentials vary in animals and humans ${ }^{21,22}$ and that wound injury potentials vary in animals, ${ }^{23}$ electrode polarity may need to be alternated during treatment to achieve an optimal rate of healing. Additional research is needed, however, not only to determine whether skin battery and wound injury potentials affect wound healing, but also to ascertain whether wound healing with ESTR is dependent on matching treatment electrode polarity with fluctuations in wound injury potential polarity. Based on studies that measured injury potentials ${ }^{19,23}$ and skin battery potentials, ${ }^{21.22}$ we were not surprised that favorable results were achieved using HVS and that our hypothesis was correct.

Physical factors such as $\mathrm{pH}$ may influence wound healing. Newton and Karselis reported that HVS (unlike continuous direct current) does not produce pH changes when applied to human skin. ${ }^{24}$ This finding suggests that clectrically induced healing from HVS may not be attributed to electrochemical phenomena. Other confounding variables such as circulatory status, medication, oxygen pressure, and age may also affect tissue repair. Additional research is needed to control these variables and to determine their effects on ESTR. Researchers also might focus on identifying other mechanisms that control ESTR.

\section{CONCLUSIONS}

A mean healing rate of $44.8 \%$ a week and the total healing of chronic wounds of patients in the Treatment Group were achieved using anodal HVS. The results of this study agrce with the literature, which indicates that ESTR from a HVS source effectively augments tissue repair and reduces the treatment costs of stage IV chronic dermal uicers. This study also extends the current literature on HVS for human subjects, further validating that ESTR is a viable method for treating patients with chronic indolent ulcers.

Acknowledgments. We thank Richard H. Jensen, PhD; Britton M. Kolar, MD; Janet Marshall, MS; Dennis C. Sobush, MA; and Gary Kolesari, MD, for their helpful criticisms. The high voltage equipment used in this study was provided by DynaWave Corp.

\section{REFERENCES}

1. Gallagher $J$, Geschickter $C$ : The use of charged gold leat in surgery. JAMA 189:928-933, 1964

2. Kanof N: Gold leaf in the treatment of cutaneous ulcers. J Invest Dermatol 43:441-442, 1964

3. Wolf $M$, Wheeler PC, Wolcott LE: Godd-leaf treatment of ischemic skin ulcers. JAMA 196:105-108, 1966

4. Carey LC, Lepley D: Elfect of continuous direct electric current on healing wounds. Surgical Forum 13:33-35, 1962

5. Wu KT, Go N, Dennis C, et al: Effects of electric currents and interfacial potentials on wound healing. J Surg Res 7:122-128, 1967

6. Assimacopoulos D: Wound healing promotion by the use of negative electric current. Am Surg 34:423-431, 1968

7. Alvarez OM, Mertz PM. Smerbeck PV, et al: The healing of superficial skin wounds is stimulated by external electrical current. J Invest Dermator $81: 144-148,1983$

B. Wolcott LE, Wheeier PC, Hardwicke HM, et al: Accelerated healing of skin ulcers by electrotherapy: Preliminary clinical results. South Med J 62:795801,1969

9. Gault WR. Gatens PF Jr: Use of low intensity direct current in management of ischemic skin ulcers. Phys Ther 56:265-269, 1976

10. Carley P. Wainapel S: Electrotherapy for acceleration of wound healing: Low intensity direct current. Arch Phys Med Rehabil 66:443-446. 1985

11. Rowley B: Electrical current effects on $E$. coli growth rates. Proc Soc Exp Biol Med 139:929-934, 1972

12. Robertson W: In Digby's receipts. Annals of Medical History 7:216-219. 1925

13. Young GH: Electric impulse therapy aids wound healing. Modern Veterinary Practice 47(14):60-62, 1966

14. Thuman BF, Christian EL: Response of a serious circulatory iesion to electrical stimulation: A case report. Phys Ther 51:1107-1110, 1971

15. Akers T, Gabrielson A: The effect of high voltage galvanic stimulation on the rate of healing of decubitus ulcers. Biomed Sci Instrum 20:99-100, 1984

16. Ross $\mathrm{CP}_{1}$ Segal D: High voltage galvanic stimulation: An aid to postoperative healing. Current Podiatry 30(5):19-25, 1981

17. Barranco $S$, Berger T: In vitro effect of weak direct current on Staphylococcus aurous. Clin Orthop 100:250-255, 1974

18. Rowley $B$, McKenna J, Chase $G$, et al: The influence of electrical current on an infecting microorganism in wounds. Ann NY Acad Sci 238:543-551, 1974

19. Becker $\mathbf{R}$ : The direct current control systern: A link between environment and organism. NY State J Med 62:1169-1176, 1962

20. Brown $M$, Gogia PP: Effects of high voltage stimulation on cutaneous wound healing in rabbits. Phys Ther 67:662-667, 1987

21. Foulds I, Barker A: Human skin battery potentials and their possible role in wound healing. Br J Dermatol 109:515-522, 1983

22. Jaffe L. Vanable J: Electric fields and wound healing. Clin Dermatol 2(3):3444, 1984

23. Burr HS, Harvey SC, Taffel M: Bio-electric correlates of wound healing Yale J Biod Med 2:103-107, 1940

24. Newton RA, Karselis $\mathrm{TC}$ : Skin $\mathrm{pH}$ following high voltage pulsed galvanic stimulation. Phys Ther 63:1593-1596, 1983 